\title{
DESIGN DE INFOGRÁFICOS NO CONTEXTO DA EDUCAÇÃO DE SURDOS: POTENCIALIZANDO O RESGATE DE CONTEÚDOS TRABALHADOS EM SALA DE AULA
}

Sergio Scolari e Renata Krusser

\begin{abstract}
O presente trabalho objetiva identificar, por meio do desenvolvimento e teste de um material didático bilíngue Libras/Português, aspectos relevantes para o projeto de infográficos voltado à educação de surdos. A grande heterogeneidade dos grupos de surdos, a falta de hábito de estudo em Libras, a dificuldade enfrentada para a leitura de textos escritos e as características da percepção e cognição visual dos surdos indicam a necessidade de se definir alguns requisitos específicos para os infográficos visando sua adequação para o estudo dos surdos. O estudo destaca a importância de se explicitar de forma muito clara a relação entre os recursos visuais e verbais, usar introdução detalhada - em língua de sinais - para contextualizar o tema, oferecer informações complementares e oportunizar a interação entre os estudantes para validarem suas observações. Os resultados sugerem que a organização da informação, a exploração da linguagem visual apropriada e a ênfase na Libras como língua de instrução podem aproximar o surdo da educação.
\end{abstract}

Palavras chave: Design, Educação de Surdos, Materiais Didáticos

Relevant aspects for infograph projects in the education of deaf people are identifiedthrough the development and testing of bilingual didactic material (Brazilian SignLanguage - Portuguese). The immense heterogeneity of deaf people, the lack of anyhabit in studying Sign Language, the difficulties in reading written texts and thecharacteristics of perception and visual cognition of deaf people require the definition ofspecific requisitions for infographs so that they could fit within the studies on deaf people. Current study underscores the relevance of making clear the relationshipbetween visual and verbal resources, detailing the introduction in sign language for thecontextualization of the theme, providing complementary information and interacting ofstudents for the validation of their observations. Results suggest that the organization ofinformation, the exploitation of proper visual language and the underscoring of Brazilian Sign Language as a lecture language may help deaf students in theirschooling.

Palavras chave: Design, Deaf Education, Educational Materials 


\section{Introdução}

O Instituto Federal de Santa Catarina, no Campus Palhoça-Bilíngue (Libras-Português), atua na educação profissional de surdos. O campus converge esforços para efetivar uma proposta educacional bilíngue, tanto no ensino presencial como no ensino à distância. Com o desenvolvimento dos cursos ofertados pela instituição verifica-se que existe uma grande carência de materiais didáticos específicos para os alunos surdos e que esse problema, além de prejudicar o processo de ensino/aprendizagem, é fator de desestímulo ao estudante surdo. Apesar do bilinguismo, ao menos em sua dimensão linguística, ser regulamentado pelo Decreto 5626 de 2005, a educação bilíngue ainda enfrenta grandes desafios e não pode ser resumida à tradução simultânea de aulas ministradas em português. É necessário que os alunos surdos tenham acesso à materiais de estudo na sua primeira língua para aprofundarem os conhecimentos ou recuperarem momentos de ausência nas aulas. A visualidade, característica fundamental da cultura e identidade surdas (QUADROS, 2005), e a modalidade visual-espacial da língua de sinais brasileira (Libras), não são exploradas satisfatoriamente pelos materiais, que em sua maioria permanecem arraigados no tradicional paradigma do texto escrito em português. Para o surdo o português aparece com status de segunda língua e sua relação com ela, por motivos históricos, políticos, e sociais, muitas vezes é de negação. Como aponta Quadros (2005): "os surdos querem aprender na língua de sinais, ou seja, a língua de sinais é a privilegiada como língua de instrução”.

Os projetos educacionais vigentes no Brasil geralmente não contemplam a diferença surda no que tange o registro dos assuntos tratados em sala de aula. A modalidade viso-espacial de comunicação, por meio da Língua Brasileira de Sinais (Libras), dificulta a visualização simultânea de outras imagens como, por exemplo, as apresentações de Power point e as figuras mostradas pelos professores. O espaço da sala de aula, principalmente na inclusão em turmas mistas de muitos ouvintes e um ou poucos surdos, cria dificuldades para o estudante surdo já que este fica impossibilitado de utilizar os canais simultâneos de visão e audição (utilizado pelos alunos ouvintes) para registrar os conceitos construídos no espaço de interação da sala de aula. Assim, além do planejamento adequado para o atendimento desses estudantes, o material didático digital bilíngue ${ }^{\mathbf{1}}$ Libras/Português surge como uma ferramenta de auxílio ao ensino, possibilitando o resgate dos principais conceitos trabalhados nas aulas.

1 O Bilinguismo tem como pressuposto básico que o surdo deve ser Bilíngue, ou seja, deve adquirir como língua materna a língua de sinais, que é considerada a língua natural dos surdos e, como Segunda língua, a língua oficial de seu país. (RIBAS, 2008)
As ferramentas digitais têm mostrado eficiência crescente na geração de interfaces multimídia. Dada a sua capacidade de comportar textos, imagens, e principalmente vídeos simultaneamente, a interface multimídia oferece recursos potenciais para atender às especificidades da modalidade linguística viso-espacial da Libras. No entanto, os projetos de interfaces digitais que se propõem acessíveis ao público surdo são raros e nem sempre eficientes.

Os infográficos desenvolvidos no âmbito digital oferecem possibilidades de exploração de recursos visuais e verbais de forma integrada, o que pode ser muito pertinente para uso na educação de surdos. Sua capacidade de condensar informações visuais sintetizando o conteúdo verbal, possibilita experimentar novas formas de pensar o material, potencializando sua eficiência e abrangência para um público específico, numeroso, e disperso na realidade de um país com dimensões geográficas continentais.

A necessidade de convergir esforços em torno do desenvolvimento de materiais didáticos bilíngues Libras/ Português torna-se evidente na medida em que se observam os dados sobre a situação escolar dos surdos brasileiros. Conforme o Censo Demográfico 2010 (IBGE, 2012) 9,7 milhões de brasileiros possuíam deficiência auditiva permanente, sendo que 344,2 mil eram surdos sem nenhuma audição e 1,7 milhões tinham grande dificuldade auditiva e 7,5 milhões possuía alguma dificuldade auditiva. Cerca de 1 milhão de pessoas com surdez profunda ou com dificuldade auditiva eram crianças e jovens de até 19 anos. No entanto, dados divulgados pelo Censo Escolar MEC/INEP 2011 (INEP, 2013), indicaram um total de 37.410 matrículas de pessoas surdas em escolas comuns e especiais e um total de 1.582 no ensino superior, um indicador do grande número de surdos à margem da escola. Atualmente, embora a Lei 5.626 obrigue as instituições públicas de ensino a possuir recursos para atender os surdos, ainda verifica-se uma forte demanda por profissionais e materiais didáticos de qualidade direcionados a este público.

Nesse sentido, o presente trabalho tem como objetivo identificar aspectos que podem contribuir com projetos de infográficos mais ergonômicos e adequados à educação de surdos. 


\section{Fundamentação}

A busca por identificar aspectos relevantes para o projeto de infográficos voltados à educação de surdos passa por uma articulação dos campos do bilinguismo, da infografia, e da ergonomia. O bilinguismo, por englobar as questões da educação, cultura e identidade surda. A infografia, pois aborda uma ferramenta comunicativa que valoriza a visualidade. E a ergonomia, por ser uma disciplina que direciona o olhar para o bem-estar dos usuários dos projetos.

\section{Bilinguismo}

De acordo com o Decreto 5626 de 2005 "São denominadas escolas ou classes de educação bilíngüe aquelas em que a Libras e a modalidade escrita da Língua Portuguesa sejam línguas de instrução utilizadas no desenvolvimento de todo o processo educativo'. Contudo, conforme aponta SILVA (2008) o bilinguismo está para além da questão linguística:

Ao trazerem a Língua de Sinais Brasileira para o debate acadêmico, os surdos, ao mesmo tempo que evidenciam as fragilidades de se pensar o ensino centrado apenas no ouvir e no falar, também procuram libertar-se das amarras da Língua Portuguesa no seu desenvolvimento intelectual. Para eles a língua de sinais não é um instrumento de comunicação para facilitar a aprendizagem da Língua Portuguesa, mas de transformação das relações sociais, culturais $e$ institucionais que geraram e geram as representações hegemônicas sobre o ser surdo no sistema de ensino. (SILVA, 2008, p. 88)

Muitos surdos também enfrentam dificuldades na leitura de textos em português e a alfabetização em português escrito exige uma metodologia própria para a aprendizagem desses estudantes. Atualmente se reconhece a importância da língua de sinais como língua de instrução para as crianças surdas nos anos iniciais de sua formação, o que também favorece a aprendizagem do português escrito como segunda língua, mas apesar da luta da comunidade surda, nem sempre é isso que acontece.

Pesquisas recentes de neuropsicologia mostram que ler é uma ação que depende tanto do reconhecimento das formas das palavras quanto da relação com o som; as duas vias de tratamento das informações (lexical e fonológica) coexistem e se complementam, e quanto menos conhecida a palavra mais recorremos à memória sonora. (SILVA, 2011); (DEHAENE, 2012).
Isso evidencia que a aprendizagem da leitura de textos em português é mais difícil para os surdos, pois se não puderem relacionar a palavra escrita com o som, terão que memorizar apenas as formas da palavra para aprenderem a ler. Além disso a estrutura da língua de sinais é muito diferente da estrutura do português o que dificulta ainda mais a leitura quando os surdos procuram traduzir o português para Libras.

As línguas de sinais também oferecem sistemas de registros que podem ser utilizados para a leitura. No entanto as características da modalidade da língua de sinais tem apresentado desafios para o seu registro. As línguas de sinais são caracterizadas pela combinação de movimentos corporais, elas "são denominadas línguas de modalidade gestual-visual (ou espaço-visual), pois a informação linguística é recebida pelos olhos e produzidas pelas mãos" (QUADROS \& KARNOPP, 2004, p.47). Quatro formas são mais difundidas para o registro de textos em Libras: o Signwriting, a ilustração, a fotografia, e o vídeo.

O Signwriting, apesar de bem aceito entre os surdos, ainda é pouco utilizado. "O sistema de escrita Signwriting - SW é um sistema complexo e adaptável às gramáticas das línguas de sinais. No Brasil, é utilizado em algumas escolas de surdos e classes bilíngues na disciplina Língua de Sinais" (SILVA (2009, p.28).

A ilustração e a fotografia são recursos estáticos e, portanto, seus principais desafios recaem sobre o como representar as diferentes posições e configurações das mãos em momentos distintos. São utilizadas principalmente para aumentar o vocabulário. $\mathrm{Na}$ aprendizagem de palavras novas, fotos ou ilustrações das configurações de mãos são usadas, geralmente acompanhadas de imagens do objeto representado pelo sinal.

O vídeo, por sua vez, consegue suplantar esta dificuldade, permitindo uma reprodução mais fidedigna dos movimentos realizados na sinalização. Com o advento da informática e democratização das tecnologias digitais o vídeo consolidou-se como uma ferramenta transformadora na qualidade de vida e comunicação da comunidade surda, promovendo a interação, educação e desenvolvimento da própria língua.

O uso de vídeos em língua de sinais é muito útil na educação e comunicação dos estudantes surdos. No entanto a bibliografia é escassa e a produção autoral de vídeos em língua de sinais é um trabalho elaborado e precisa ser feita levando em consideração alguns aspectos específicos da percepção e cognição visual dos surdos.

A heterogeneidade dos grupos de surdos precisa ser considerada. Em um grupo de surdos é comum 
encontrarmos estudantes que vivem em famílias de ouvintes que não sabem a língua de sinais e que se comunicam com o surdo apenas por gestos e mímicas. Muitos surdos possuem um vocabulário limitado na língua de sinais e dificuldade para ler em português. Enquanto alguns surdos só aprenderam uma língua em idade avançada, outros são oralizados e dominam a língua de sinais e o português escrito. Alguns surdos contaram com o trabalho de tradutores intérpretes na inclusão escolar ou estudaram em escolas bilíngues, além de ter acompanhamento familiar dedicado e participar de grupos de surdos. Outros viveram muito isolados ao longo da vida e experimentam uma realidade caótica em escolas despreparadas para a educação de surdos. Portanto ao abordar a educação de surdos é importante considerar a variedade nas características dos surdos, tanto em relação à proficiência linguística como em relação ao seus conhecimentos prévios para compreenderem os temas abordados.

Os surdos tem uma forma de orientação no mundo que privilegia os aspectos visuais e geralmente possuem um campo de visão mais amplo e uma visão periférica mais apurada que os ouvintes (BAUMAN, 2008), (BUCKLEY et al, 2010).

Apesar disso, muitas vezes o que os surdos encontram são imagens soltas, sem referências, sem outras informações sobre seu conteúdo, sem uma orientação educadora, sem discussão. Enquanto as crianças ouvintes escutam os comentários, opiniões e informações complementares, mesmo que não sejam direcionadas para elas, muitos surdos precisam fazer suposições sobre o significado das coisas sozinhos e apenas a partir do que veem.

Para se conhecer alguma coisa não basta olhar, é necessário diferenciar essa coisa de outras, contextualizar, relacionar, comparar, organizar, enfim, produzir sentidos. A aprendizagem não acontece de forma espontânea pelo olhar solitário de uma criança surda, exige diálogo e intencionalidade, como coloca FALCÃO (2010):

A cognição visual não se trata do olhar comum, sem intencionalidade, com simplicidade e simplificação, do "olhar por olhar", ver e já pensar que aprendeu, entendeu, compreendeu e que com isso já domina o conhecimento concreto e abstrato, objetivo e subjetivo, sua forma, função, estrutura, ação, variáveis, sentimentos, como se fosse, o conhecimento, apropriado e apreendido por osmose e naturalmente pela simplicidade do olhar contemplativo sem ser investigativo, curioso, pesquisador, crítico (...) FALCÃO (2010, p.147).

O autor chama a atenção para a importância da descrição visual sinalizada na educação das crianças surdas, motivando-as para a aprendizagem. Considera fundamental esse diálogo intencional para que que os estímulos visuais possam vir a assumir funções linguísticas e cognitivas.

As imagens, por si só, pouco se apresentam como ferramentas comunicacionais, educadoras $e$ construtoras de significados com vistas à plenitude cognitiva pois devem ser trabalhadas diferenciadamente para esta conquista. (FALCÃO, 2010, p.161).

A cognição visual não é um processo isolado da língua, mesmo que os significados possam se estabelecer a partir dos recursos visuais. Para se contribuir de forma mais efetiva com a aprendizagem é importante explorar a relação entre imagens ou entre imagens e palavras, num processo de comunicação planejado e intencional.

Os infográficos digitais podem ser utilizados com os vídeos em língua de sinais, oferecendo conteúdo verbal e visual de forma integrada e complementar. Os infográficos permitem também integrar os textos em Libras com os textos em português e com outras manifestações gráficas para a apresentação de conteúdos específicos em materiais didáticos. O desenvolvimento de peças gráficas compostas por este conjunto de diversos tipos de informação é escopo dos estudos da área de infografia.

\section{Infografia}

A infografia consolida-se como uma importante ferramenta da comunicação contemporânea. Atualmente os infográficos estão presentes em impressos: jornais, revistas, folhetos, entre outros, bem como em formatos digitais, apresentados por meio de monitores: tvs, computadores, telefones celulares, tablets etc. Segundo Sancho (2001), pode-se dizer que um infográfico é uma contribuição informativa, realizada com elementos icônicos e tipográficos, que permite ou facilita a compreensão de acontecimentos ou ações ou alguns de seus aspectos mais significativos, e acompanha ou substitui o texto informativo. Pode-se também afirmar que existe há pelo menos 200 anos, mas a informática a tem potencializado muito. De acordo com Leturia (1998) os infográficos podem dividir-se nas seguintes categorias: gráficos, mapas, tabelas e diagramas. Os gráficos são os mais comumente utilizados e mostram informações numéricas e estatísticas. Eles se dividem em gráfico de barras, que funciona preferencialmente para comparação de unidades; gráfico de setores, que indica a divisão de partes de um todo e suas proporções, especialmente em porcentagens; e gráfico de linhas, que mostra as mudanças, expressadas em números, através do tempo. Os mapas são usados para mostrar a localização de determinado acontecimento. As tabelas tem como principal função apresentar informações 
resumidas do conteúdo textual. Já os diagramas servem para mostrar como se vê ou como algo funciona, podendo utilizar-se de legendas e diferentes perspectivas de observação para as representações.

Os infográficos já são bastante explorados na educação, tanto em livros didáticos como em recursos digitais, entretanto esses materiais raramente levam em consideração os aspectos específicos dos estudantes surdos e não atendem a demanda por materiais bilíngues Libras/português.

O projeto de infográficos contemplando duas modalidades linguísticas diferentes (auditiva-oral e espaço-visual) para comunicar o conteúdo textual é algo que apenas recentemente tem sido estudado.

Um estudo importante sobre o tema é a tese de Lapolli (2014): Visualização do conhecimento por meio de narrativas infográficas na web voltadas para surdos em comunidades de prática. A autora recomenda que as narrativas infográficas na web devem:

- ser criativas despertando a curiosidade do estudante;

- ter elementos persuasivos e informativos;

- as telas devem ser o mais o simples possível, tanto em forma como em conteúdo;

- usar pouco texto, apenas um título ou um texto explicativo em cada tela para que se saiba qual é o seu objetivo;

- ter uma interface de abertura que serve de sumário indicando o que tem dentro do documento;

- os ícones devem ser rapidamente entendidos e relacionados ao quevai acontecer quando clicado;

- deve haver uma hierarquia na apresentação dos links, estando ativos primeiro os que acessam conteúdos mais simples, à medida que complexidade aumenta novos links vão sendo ativados;

- as imagens devem dar ênfase às explicações mais importantes e não devem ser usadas imagens meramente decorativas;

- a tipografia deve ser clara e concisa;

Lapolli (2014) destaca também a importância de incluir a tradução dos textos para Libras.

Neste estudo elaboramos um protótipo de infográfico para os testes com estudantes surdos, tendo como foco o uso em sala de aula ou como material para estudo complementar aos conteúdos estudados em aula. O desenvolvimento de infográficos bilíngues Libras/português exige uma atenção especial quanto à ergonomia.

\section{Ergonomia}

A ABERGO - Associação Brasileira de Ergonomia apresenta em seu site (www.abergo.org.br) a definição adotada pela IEA - Associação Internacional de Ergonomia (www.iea.cc), que diz: "A Ergonomia (ou Fatores Humanos) é uma disciplina científica relacionada ao entendimento das interações entre os seres humanos e outros elementos ou sistemas, e à aplicação de teorias, princípios, dados e métodos a projetos a fim de otimizar o bem estar humano e o desempenho global do sistema”. Para Gomes Filho (2003) "[...] a ergonomia objetiva sempre a melhor adequação ou adaptação possível do objeto aos seres vivos em geral. Sobretudo, no que diz respeito à segurança, ao conforto e à eficácia de uso ou de operacionalidade dos objetos, mais particularmente, nas atividades e tarefas humanas".

Os infográficos são ferramentas que exploram fortemente a comunicação visual. Dul \& Weerdmeester (2004) apresentam algumas diretrizes para adequar as informações visuais à capacidade de percepção dos olhos: Evite textos com todas as letras maiúsculas; os alinhamentos à direita não devem deixar espaços em branco; use tipos de letras simples; evite confusão entre letras; as letras devem ter tamanho adequado; as linhas longas exigem maior espaçamento entre elas; um bom contraste ajuda na legibilidade; produza gráficos de fácil entendimento; use símbolos com cuidado; selecione um mostrador adequado. Nota-se que para os textos escritos já existem algumas diretrizes, mas elas se mantêm quando acrescentamos textos sinalizados para dialogar com os outros elementos gráficos e tipográficos? Qual vem primeiro? Em quais tamanhos? Onde posicionar? É mais funcional e confortável os textos aparecerem em pequenas janelas junto às imagens ou separado em uma janela maior com a sinalização do intérprete? Tais perguntas apresentam um campo de investigação vasto, fértil e carente de estudos.

A busca por uma didática visual emerge em consonância com as atribuições do designer atual, como aponta Bonsiepe (2011) "[...] Portanto, não é suficiente produzir conhecimentos. Os conhecimentos devem também ser organizados, apresentados e comunicados, de uma forma apropriada, utilizando a tecnologia disponível."

\section{Desenvolvimento}

O A partir do mapeamento bibliográfico iniciou-se o processo de design de um infográfico com o objetivo de investigar sua adequação ergonômica para o estudo dos alunos surdos. O tema escolhido foi “diafragma”, um mecanismo da câmera fotográfica, 


\footnotetext{
2 Análise paramétrica, também conhecida como Análise Sincrônica ou Análise de Concorrentes e Similares (ACS), é uma ferramenta de análise que serve para comparar aspectos quantitativos e qualitativos de produtos em desenvolvimento com produtos existentes ou concorrentes, avaliando-os a partir de variáveis mensuráveis.
}

um conteúdo que faz parte da unidade curricular de fotografia, ministrada no segundo módulo do Curso Técnico Integrado em Comunicação Visual do IFSC Campus Palhoça-Bilíngue. Para o desenvolvimento seguiram-se as fases propostas por Lobach (2001): Preparação, Geração, Avaliação, Realização.

\section{Preparação}

De acordo com Lobach (2001) essa fase envolve o conhecimento do problema, coleta e análise de informações e definição de critérios para o novo produto.
Foram realizadas a coleta de informações bibliográficas sobre a função do mecanismo e os efeitos gráficos provenientes de sua manipulação. Em seguida mapearam-se os similares em livros e manuais de fotografia, bem como na internet, totalizando catorze infográficos contendo o assunto diafragma. Oito desses infográficos tinham estruturas muito parecidas, assim foi selecionado um deles baseando-se em critérios de legibilidade e pregnância para ser analisado. Em dez dos similares o assunto diafragma estava relacionado com os outros dois mecanismos envolvidos na Exposição Fotográfica, a saber, obturador e ISO. A Figura 1 mostra os principais similares mapeados.
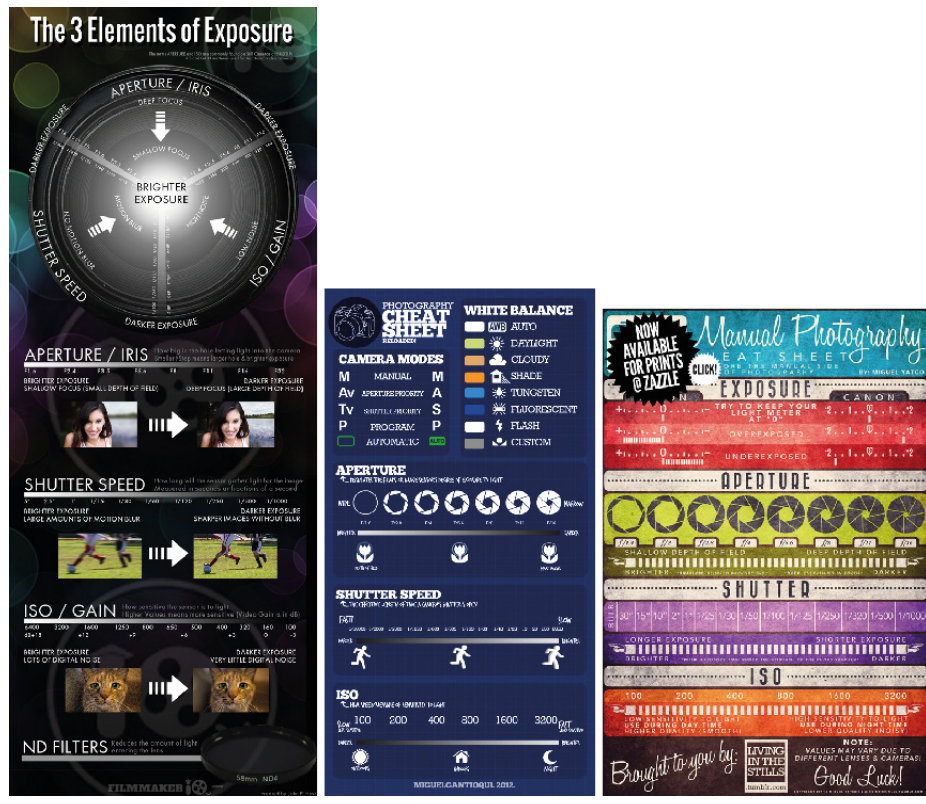

Figura 1: Principais similares mapeados.Fonte: http://www.hongkiat.com/blog/cheetsheets-for-photographers.

Iniciou-se então uma análise paramétrica ${ }^{2}$, conforme descrita por Pazmino (2010), com os seguintes critérios: estilo, funcionalidade/usabilidade, cor, formato, dimensões e quantidade de conteúdo textual em relação ao conteúdo gráfico. Em seguida classificaram-se as informações que constavam nos infográficos a fim de saber quais eram expostas com maior frequência. Os resultados foram analisados junto ao mapeamento bibliográfico e resultaram nos seguintes critérios para o novo produto:
- Apresentação das seguintes informações: nome do mecanismo; descrição sintética de sua função; escala numérica encontrada na câmera fotográfica; e efeitos fotográficos advindos das possibilidades de ajustes diferentes apresentadas em forma de escala - claro x escuro e profundidade de campo.

- Apresentação das informações em Libras, em Português e por meio de recursos gráficos/ visuais. 
3 MESCRAI é uma

ferramenta para o estímulo da criatividade que funciona como uma lista de verificação para estimular possíveis modificações no produto a partir de variáveis mensuráveis.
4 Brainwriting 635 é uma ferramenta para estímulo da criatividade que tem por objetivo buscar soluções para problemas de projeto por meio de uma equipe multidisciplinar fazendo o uso de um formulário.

5 Cada participante recebeu 5 votos que puderam distribuir entre as ideias que lhe pareceram mais promissoras. No final discutiram-se sobre as mais votadas.
- Navegação simples, sem a necessidade de links para ambientes externos ao material proposto.

- Foco no uso da cor como informação.

- Ênfase no uso da linguagem visual à escrita para a comunicação.

\section{Geração e Avaliação}

Conforme Lobach (2001) a fase de geração envolve a escolha dos métodos de solucionar problemas; produção de ideias e geração de alternativas. Já na fase de avaliação estão envolvidos o exame das alternativas, o processo de seleção e o processo de avaliação.
$\mathrm{Na}$ geração, as alternativas propostas seguiram um olhar de tradução das informações textuais e visuais apresentadas nos similares analisados, buscando uma composição gráfica que priorizasse a visualidade. Esse olhar foi estimulado pelo uso da ferramenta MESCRAI ${ }^{3}$, como descrita em Baxter (2011). Também desenvolveu-se um brainwriting $635^{4}$ como em Panzimino (2010), com fim de estimular a geração coletiva de idéias.

A partir dos desenhos gerados iniciou-se a primeira etapa da avaliação, em que as idéias mais adequadas foram selecionadas por votação ${ }^{5}$, como proposta por Baxter (2011). Ao final dessa etapa foram elencadas as três melhores idéias. As três alternativas passaram por uma nova avaliação, em que foram examinadas individualmente e pontuados seus pontos fortes e fracos. Uma síntese dessa análise é apresentada a seguir.
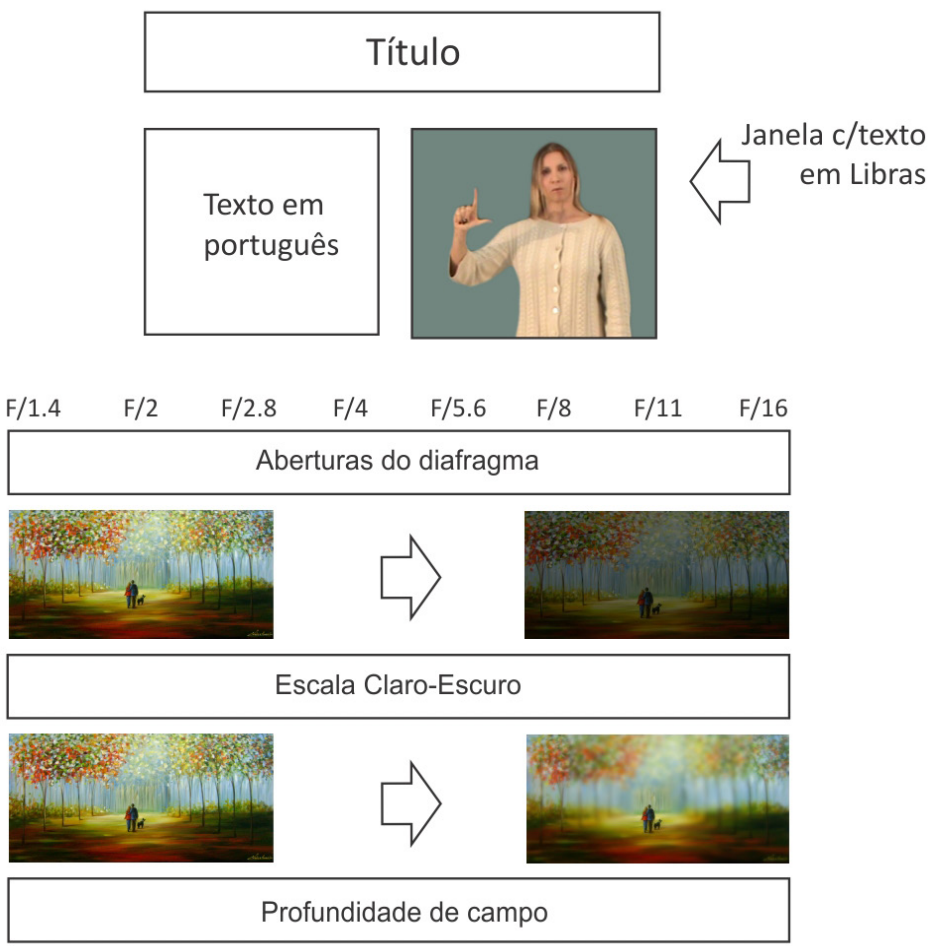

Figura 2: Infográfico bilíngue - alternativa 1. Fonte: Elaborado pelos autores.

A primeira alternativa selecionada (Figura 2) remonta às estruturas dos similares diminuindo as expressões em línguas orais e transmitindo esse conteúdo pelos gráficos. Permite uma visualização ampla das informações, no entanto apresenta uma fraca relação entre o texto e as imagens. 


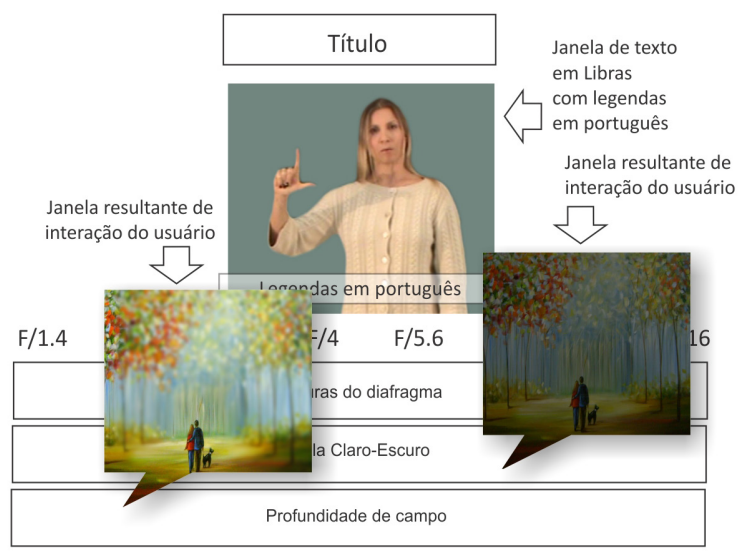

Figura 3: Infográfico bilíngue - alternativa 2. Fonte: Elaborado pelos autores.

A alternativa 2 (Figura 3) é interativa. As janelas resultantes da interação acabam encobrindo parte das informações do restante do material.

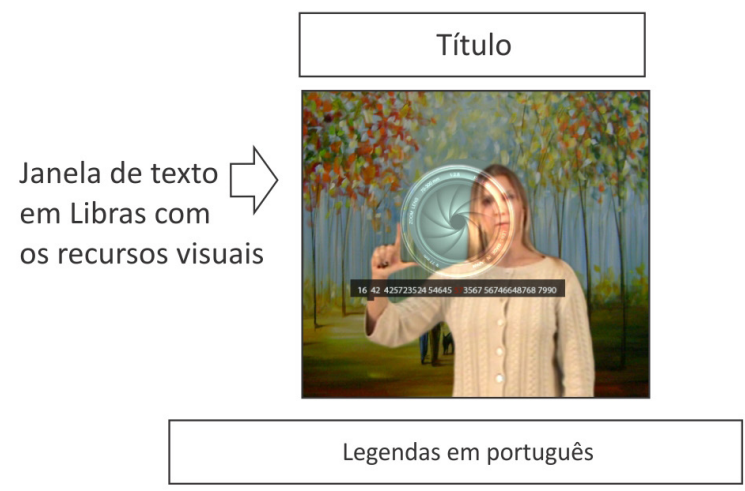

Figura 4: Infográfico bilíngue - alternativa 3. Fonte: Elaborado pelos autores.

Na alternativa 3 (Figura 4), os elementos da máquina fotográfica e o resultado de sua manipulação são apresentados com elementos gráficos integrados aos movimentos do intérprete e os efeitos que promovem são mostrados na fotografia de fundo. $\mathrm{O}$ uso de muitas imagens simultaneamente pode dificultar a leitura. A apresentação do conteúdo do infográfico ao longo do vídeo impõe o ritmo do intérprete na leitura e o leitor não tem uma informação imediata das possibilidades oferecidas pelos recursos da câmera. Também torna mais difícil a localização de uma informação específica ao longo do vídeo.
Em seguida, as estratégias avaliadas positivamente nas alternativas foram reunidas em uma alternativa final, que foi desenvolvida na fase de realização.

\section{Realização}

De acordo com Lobach (2001) essa fase envolve a realização da solução do problema e nova avaliação da solução. 
A alternativa final buscou convergir as seguintes características: a estrutura gráfica da alternativa 1, a interação com o produto da alternativa 02 e a relação forma-conteúdo apresentada no vídeo da alternativa 03. A Figura 5 mostra o resultado.

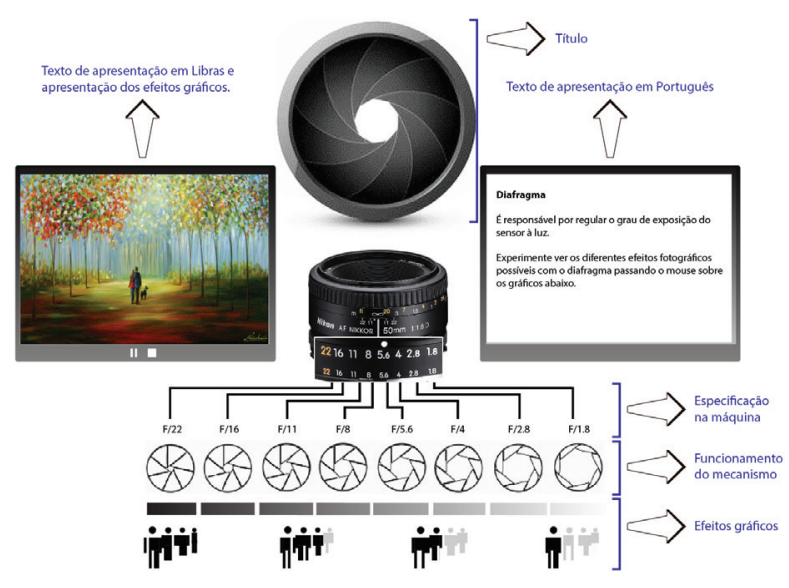

Figura 5: Protótipo do infográfico. Fonte: Elaborado pelos autores.

6 O alfabeto manual representa as letras do alfabeto das línguas orais. É usado por surdos para identificar nomes próprios e palavras da língua portuguesa, quando necessário. (QUADROS \& KARNOPP, 2004).

\section{Sinal é uma} expressão visual do nome.

\section{Testes com os estudantes surdos}

Concluídas as etapas de geração e avaliação das alternativas, com uma alternativa final já com os textos em Libras e a interatividade do material funcionando (protótipo), passou-se para os testes de leitura com os surdos. As avaliações foram feitas em dois momentos: com um grupo focal, que ainda não tinha cursado a unidade curricular de fotografia, e com um grupo de estudantes que já tinham cursado a disciplina e usaram e avaliaram o infográfico individualmente.

Nos testes, inicialmente, a atividade foi contextualizada, explicando o procedimento e os objetivos aos participantes. A seguir o infográfico foi dispo- nibilizado para a interação.

Foram feitas as seguintes perguntas para que, com auxílio do infográfico, os participantes respondessem:

1. Como ajustar o diafragma para focar um objeto que está próximo e desfocar o fundo da imagem?

2. O que ocorre com a imagem quando ajustamos o diafragma para $\mathrm{F} / 22$ ?

3. Por que a imagem fica mais clara quando o diafragma está ajustado em $\mathrm{F} / 1.8$ ?

4. Você notou diferença deste material para os que você normalmente utiliza para resgatar os conteúdos trabalhados em sala de aula? Se notou, achou mais fácil ou mais difícil de usar? 5. O que você mudaria no material?

No primeiro teste, com o Grupo focal, participaram quatro surdos profundos, sendo dois masculinos e dois femininos, entre catorze e dezoito anos de idade, residentes da cidade de Palhoça-SC, alunos do curso técnico integrado de Comunicação visual.

O Grupo Focal é uma ferramenta qualitativa que permite levantar necessidades e desejos dos usuários na avaliação de protótipos desenvolvidos (PAZMINO, 2010). 
Depois da apresentação da proposta os estudantes se apresentaram e o infográfico foi disponibilizado. Iniciou-se a discussão analisando os aspectos gráficos e linguísticos da ferramenta. Os estudantes trocaram ideias e discutiram sobre o material.

No segundo teste, os estudantes foram orientados individualmente sobre a proposta do material e da pesquisa. O teste foi feito com a presença do professor e de um tradutor intérprete que contribuiu para registar as respostas dos estudantes em português, mas não houve discussão entre eles sobre

Participaram três estudantes surdos, também do curso técnico em Comunicação visual, com idades entre 16 e 18 anos, sendo dois masculinos e um feminino. Todos já tinham cursado a unidade curricular de fotografia.

A seguir são apresentados e discutidos os resultados.

\section{Resultados e Discussão}

A iniciativa de produção de um material didático voltado aos alunos surdos foi muito bem recebida pelos participantes, que mostraram-se interessados na nova ferramenta.

Os surdos, que ainda não haviam feito o curso de fotografia, tiveram dificuldade em contextualizar o conteúdo do infográfico, uma vez que o mecanismo foi apresentado isoladamente dos outros elementos da câmera. Assim, a informação sintética apresentada no texto em Libras não foi suficiente para os alunos.

Em relação às perguntas realizadas para verificar a eficácia do material os participantes do Grupo focal foram assertivos nas respostas, ora manipulando o infográfico ora apenas olhando para ele. É importante observar as discussões geradas acerca do tema entre os estudantes, que no intercâmbio de suas diferentes experiências construíram uma concepção válida sobre o diafragma, suas funções e efeitos gráficos provenientes de sua manipulação. Eles atribuíram mais ênfase na leitura do texto em Libras do que à estrutura visual proposta. Pouca ou nenhuma atenção foi dada ao texto em português. Os estudantes que já conheciam o funcionamento de uma câmera fotográfica não mostraram maior facilidade para interagir com o mecanismo. Após assistirem o vídeo em Libras que orienta à usar a ferramenta interativa dois estudantes aguardaram uma orientação do professor incentivando a experimentação.
Um estudante considerou difícil a compreensão do recurso, mas comentou que junto com a câmera fotográfica poderia contribuir para o entendimento de seu funcionamento. Todos interagiram passando o mouse sobre as escalas gráficas e reconheceram as alterações na imagem, mas na resposta da questão que perguntava porque a imagem fica mais clara quando o diafragma está ajustado em F/1.8, apenas um estudante relacionou a abertura da lente com os efeitos na imagem.

A partir disso é possível apontar que: para o projeto do material é necessária uma ênfase na contextualização do tema e que o texto em português pode atuar como suporte à comunicação, não demandando a ocupação das áreas privilegiadas de uma composição.

A estrutura gráfica mostrou-se suficiente para a navegação, mas com possibilidade de ser melhorada em termos de clareza e usabilidade. A navegação nas escalas gráficas foi proposta com o mouse passando em cima (roll over), enquanto os usuários insistiram na tentativa de clicar sobre as imagens. Tornar mais explícitas as escalas gráficas seria uma primeira modificação para o avanço da ferramenta. Isso indicou a importância da navegação ser simples e clara, com a interatividade baseada em cliques do mouse, e uma boa diferenciação entre aquilo que é clicável ou não.

O tamanho da janela disponível para o texto em Libras não foi um problema para os participantes. Assim, entende-se que elas devem permitir a identificação das expressões faciais, configurações de mãos e movimentos corporais do sinalizante, ficando em segundo plano o critério de área da composição ocupada pela janela.

Também foi destacada a preferência dos estudantes por utilizarem materiais que utilizam a língua de sinais, além da exploração de recursos visuais.

Com a eficácia da ferramenta no estudo com os surdos para a elaboração de uma concepção sobre o diafragma, foi possível identificar a adequação desta proposta de infográfico como uma possibilidade de resgatar os conhecimentos trabalhados em sala de aula. Ainda, identificou-se a necessidade deste tema ser articulado com os outros mecanismos responsáveis pela exposição fotográfica em uma câmera.

\section{Considerações Finais}

Com a criação da Lei $\mathrm{N}^{\circ} 10.436$, que dispõe sobre a Língua Brasileira de Sinais, em 2002, e sua regulamentação com o Decreto $\mathrm{N}^{0}$ 5.626, em 2005 , 
garantiu-se a presença da Libras nas instituições de ensino brasileiras. Este movimento incentivou a consolidação da pesquisa nesta área no âmbito acadêmico nacional. Os esforços iniciais concentraram-se nas áreas da linguística e tradução/ interpretação. No contexto do desenvolvimento tecnológico as pesquisas ainda são incipientes. Este projeto configura-se como uma experiência de aproximação das tecnologias digitais e de produção gráfica com a cultura visual dos surdos. $\mathrm{O}$ início das discussões envolvendo infografia e bilinguismo promove o avanço teórico-metodológico numa interface que dissolve atuais fronteiras de ambas as áreas.

Verifica-se que a organização da informação, a exploração da linguagem visual apropriada e a ênfase na Libras como língua de instrução nos materiais didáticos podem aproximar o surdo da educação, contribuindo para a formação profissional, promovendo a autonomia e garantindo o direito de exercer sua cidadania.
Observa-se que a interação entre os estudantes que não tinham conhecimento prévio do equipamento apresentado no infográfico foi muito importante e facilitou a compreensão dos recursos, o que está de acordo com o que pesquisadores como Lapolli (2014), Saito (2016), entre outros, tem destacado. Favorecer a comunicação e valorizar o estudo em comunidades de prática têm se mostrado motivador e produtivo para a aprendizagem dos estudantes surdos.

Visando a evolução do material sugere-se investigar as possibilidades de sintetizar os três mecanismos em um único infográfico, para que o aluno que já tenha apreendido os conceitos que envolvem cada uma das ferramentas possa avançar no processo de entendimento da combinação dos recursos da câmera e atingir os efeitos fotográficos desejados.

Para trabalhos futuros, consideramos importante aprofundar a análise da relação entre imagens e a janela em língua de sinais, observando a eficiência e a preferência dos surdos ao integrar imagens ao vídeo em língua de sinais, sejam como fundo ou articuladas com os movimentos do intérprete.

\section{Referências}

BAUMAN, H-Dirksen (Ed.). Open your eyes: deaf studies talking. Minneapolis: University of Minnesota, 2008.

BAXTER, M. Projeto de produto: guia prático para o design de novos produtos. 3. ed. São Paulo: Blucher, 2011.d

BONSIEPE, G. Design, Cultura e Sociedade. São Paulo: Blucher, 2011.

BUCKLEY, D. et al. Action video game players and deaf observers have larger Goldmann visual fields. Vision Research, v. 50, n. 5, p. 548-556, 2010.

DECRETO No 5.626 - <Disponível em http://www.planalto.gov.br/ccivil_03/_ato20042006/2005/decreto/d5626.htm>

DEHAENE, Stanislas. Os neurônios da leitura: como a ciência explica a nossa capacidade de ler. Tradução de Leonor Scliar-Cabral. Porto Alegre: Penso, 2012.

DUL, J.; WEERDMEESTER, B. Ergonomia Prática. 2.ed. rev. e ampl. São Paulo: Edgard Blucher, 2004.

FALCÃO, Luiz Albérico. Surdez, cognição visual e Libras: estabelecendo novos diálogos. Recife: Ed. Do autor, 2010. 
GOMES FILHO, João. Ergonomia do objeto: sistema prático de leitura ergonômica. São Paulo: Escrituras Editora, 2003.

LEI № 10.436 - <Disponível em http://www.planalto.gov.br/ccivil_03/Leis/2002/ L10436.htm>

LAPOLLI, Mariana. Visualização do conhecimento por meio de narrativas infográficas na web voltadas para surdos em comunidades de prática. p. 277. 2015. Tese (Doutorado). Programa de Pós- Graduação em Engenharia e Gestão do Conhecimento. Universidade Federal de Santa Catarina. Florianópolis, 2015.

LETURIA, E.. ¿Qué es infografia?. Revista Latina de Comunicación Social. v. 4, 1998. Disponível em: http://www.ull.es/publicaciones/latina/z8/r4el/htm

LOBACH, B.. Desenho Industrial: bases para a configuração de produtos visuais. São Paulo: Edgard Blücher, 2001.

MEC. Direito à Educação - Subsídios para a Gestão dos Sistemas Educacionais - Orientações Gerais e Marcos Legais. Ministério da Educação/Secretaria de Educação Especial. 2a. Edição. Brasília. 2006. Disponível em: <http://portal.mec.gov.br/seesp/arquivos/pdf/direitoaeducacao. Pdf $>$

PAZMINO, Ana Verônica. Modelo de ensino de métodos de design de produtos. 2010. 454 f. Tese (Doutorado) - Curso de Pós-graduação em Design, Departamento de Artes e Design, Pontifícia Universidade Católica do Rio de Janeiro, Rio de Janeiro, 2010.

QUADROS, R. M. de. O bi do bilingüismo na educação de surdos In: Surdez e bilingüismo.1 ed. Porto Alegre: Editora Mediação, 2005, v.1, p. 26-36.

QUADROS, R. M.; KARNOPP, L. B.. Língua de sinais brasileira: estudos linguísticos. Porto Alegre: Artmed, 2004.

RIBAS, A. C. A Interface do Ambiente Virtual de Ensino Aprendizagem do Curso LetrasLibras segundo as características da cultura surda e os critérios de usabilidade. Dissertação de Mestrado. Design e Expressão Visual, UFSC. 2008.

SAMAIN, Etienne (Org.). Como pensam as imagens. Campinas: Unicamp, 2012.

SANCHO, J. L. V.. La infografía: Técnicas, análisis y usos periodísticos. València : Universitat de València, 2001.

SAITO, Daniela. Ambientes de comunidades de prática virtuais como apoio ao desenvolvimento de neologismos. p. 285. 2016. Tese (Doutorado). Programa de PósGraduação em Engenharia e Gestão do Conhecimento. Universidade Federal de Santa Catarina. Florianópolis, 2016.

SILVA, F. Analisando o processo de leitura de uma possível escrita da língua brasileira de sinais: Signwriting. Dissertação de Mestrado. UFSC. Florianópolis. 2009. 
SILVA, Vilmar. As representações em ser surdo no contexto da educação bilíngue. In: QUADROS, R. M. de. (Org). Estudos surdos III. Série pesquisas. Petrópolis: Arara-Azul, 2008. p. 8

SILVA, Ezequial T. O ato de ler: fundamentos psicológicos para uma nova pedagogia da leitura. São Paulo: Cortez, 2011. 